Research Article

\title{
Degradation of High-Concentration Nitrate Nitrogen in Groundwater: A Laboratory Study
}

\author{
Manxi Liu, ${ }^{1}$ Lu Xia, ${ }^{1}$ Ruinan Liu, ${ }^{1}$ Zongjun Gao $\left({ }^{1},{ }^{1}\right.$ Cong Han, ${ }^{1}$ \\ Jianguo Feng, ${ }^{1}$ Jing Wang, ${ }^{1}$ Wanlong $Q \mathbf{u},{ }^{2,3}$ and Tongju Xing ${ }^{2,3}$ \\ ${ }^{1}$ College of Earth Science and Engineering, Shandong University of Science and Technology, Qingdao, China \\ ${ }^{2}$ Qingdao Geo-Engineering Surveying Institute (Qingdao Geological Exploration and Development Bureau), Qingdao, China \\ ${ }^{3}$ Key Laboratory of Urban Geology and Underground Space Resources, \\ Shandong Provincial Bureau of Geology and Mineral Resources, Qingdao, China
}

Correspondence should be addressed to Zongjun Gao; zongjungao1964@163.com

Received 12 April 2021; Revised 13 May 2021; Accepted 22 May 2021; Published 29 May 2021

Academic Editor: Junbing $\mathrm{Pu}$

Copyright (c) 2021 Manxi Liu et al. This is an open access article distributed under the Creative Commons Attribution License, which permits unrestricted use, distribution, and reproduction in any medium, provided the original work is properly cited.

To investigate effective and reasonable methods for the remediation of nitrate nitrogen pollution in groundwater, two groups of laboratory denitrification experiments were conducted: one on the effect of native denitrifying microbes in groundwater and another on the effect of artificially added denitrifying microbes. The water used in the experiment was typical groundwater with a high concentration of nitrate nitrogen. The temperature was controlled at $15^{\circ} \mathrm{C}$. Both groups of experiments established four types of culture environments: anaerobic, anaerobic with an added carbon source (glucose), aerobic, and aerobic with an added carbon source (glucose). The results indicated that native denitrifying microbes in the groundwater have almost no ability to remove high concentrations of nitrate nitrogen. However, artificially added denitrifying microbes can effectively promote denitrification. Artificially added denitrifying microbes had the highest activity in an anaerobic environment in which a carbon source had been added, and the rate removal of a high concentration of nitrate nitrogen in groundwater was the highest and reached as high as $89.52 \%$.

\section{Introduction}

Groundwater is an important part of water resources, with a stable quantity of high-quality water. It is one of the important water sources for agricultural irrigation, industry, mining, and urban life. However, with the development of society and economy and the influence of human activities, increasing amounts of environmental pollution problems have gradually been exposed, particularly the pollution of groundwater, whose scope has expanded from point to surface and from shallow to deep. In addition, the number of types of pollutants has been increasing. The degree of pollution is becoming increasingly serious [1-4]. Owing to the discharge and leakage of domestic sewage and substandard industrial wastewater, an unreasonable recharge of sewage, the leaching of fecal and solid waste, the application of a large number of chemical fertilizers and pesticides in rural areas, dry and wet deposition of nitrogen oxides in the atmosphere, and excessive exploitation of groundwater, the concentration of nitrate nitrogen in groundwater has been increasing, thus, resulting in serious pollution to the environment [5-8]. Groundwater with a high concentration of nitrate nitrogen poses a major threat to human beings and other organisms, since the excessive intake of nitrate results in its reduction to toxic nitrite in the human body [9-11], which can be further transformed into nitrosamines. $\mathrm{Ni}$ trosamine is a "three-cause" substance, which easily causes digestive system diseases, methemoglobinemia (blue baby disease), and other problems [12-15].

The problem of nitrate pollution of groundwater has aroused widespread concern in academic circles. The effective remediation of nitrate pollution of groundwater has become the focus of widespread concern. The conventional processes (flocculation sedimentation-filtration-chlorine disinfection) applied for water potability do not eliminate nitrate from the groundwater [16], and special treatment 
processes are required to lower the concentration of nitrate to acceptable levels. Currently, the main remediation methods of nitrate pollution in groundwater are physical, chemical, and biological methods. Although there are many methods, each has its own limitations in practical application [17-20]. In terms of eliminating nitrate pollution in groundwater and reducing the cost of denitrification, the biological method is the most effective method that is currently used [21, 22]. This method is characterized by high efficiency and low consumption, so it has been extensively studied. Bioremediation methods primarily rely on the denitrification of microorganisms to remove pollutants from groundwater $[23,24]$. Most of the denitrifying microbes involved in the denitrification process are heterotrophic facultative anaerobes, which cannot synthesize organic matter themselves and need to consume additional carbon sources to produce energy and conduct cell synthesis and deoxidation [25]. Currently, the research on bioremediation methods is primarily focused on the selection of denitrifying microbes and carbon sources.

Trudell et al. [26] conducted a large number of experiments that proved that solid organic carbon can also be used as a substrate for denitrification. Schipper et al. [27], Robinson-Lora et al. [28], and Moorman et al. [29] selected solid carbon sources for denitrification experiments and achieved good denitrification results. However, solid carbon sources are mostly natural materials, such as sawdust, rice straw, and bark, and their carbon release is uncontrollable, which easily causes secondary pollution, aquifer blockage, and other problems [30, 31]. Compared with solid carbon sources, liquid carbon sources have a fast dissolution rate and highly efficient reactions. Studies have shown [32-39] that common carbon sources, such as methanol, ethanol, acetic acid, sucrose, and glucose can promote denitrification. In addition, different carbon sources have varying effects on denitrification. There are also many studies on denitrifying microbes [40-43]. Wang et al. [44] successfully isolated denitrifying microbes from groundwater in intensive vegetable growing areas. Zhang et al. [45] isolated denitrifying microbes from soil and verified their ability to perform denitrification. Using a shaking flask experiment, Wang [46] revealed that the groundwater polluted by nitrate contains a large number of indigenous microorganisms, which can degrade the nitrate in the presence of an additional carbon source. Li et al. [47] showed that the sludge of the anaerobic section of a sewage treatment plant contains denitrifying microbes, which are highly active after enrichment and culture. Zhang et al. [37] and Zhang et al. [38, 39] proved that the combination of optimized artificial denitrification agents and common carbon sources such as ethanol can clearly remove nitrate pollution from groundwater. Previous studies have made substantial progress in verifying that both liquid and solid carbon sources can promote denitrification. There is denitrification by indigenous microorganisms in groundwater, which can be enhanced by adding carbon sources to degrade nitrate pollution. Biological bacteria and fungi are beneficial for removing nitrate nitrogen in groundwater. However, research mostly adopts groundwater and synthetic water with low concentrations of nitrate nitrogen. There are few research results on the comparison of effects of native denitrifying microbes in groundwater with those that have been artificially added on the remediation of groundwater with a high concentration of nitrate nitrogen. In view of these considerations, this study selected glucose as the carbon source and attempted to investigate the effect of the denitrification of native denitrifying microbes in groundwater and artificially added denitrifying microbes under different combinations of oxygen and carbon sources.

\section{Materials and Methods}

2.1. Sampling. Studies have shown that, owing to the longterm application of nitrogen fertilizer in vegetable growing areas, the content of nitrate nitrogen in groundwater is very high. The water used in the experiments was taken from the groundwater in a vegetable growing area $\left(36.71565^{\circ} \mathrm{N}\right.$, $120.31963^{\circ} \mathrm{E}$ ), and the sampling depth was $5 \mathrm{~m}$. After sampling on the spot, the water was placed into a polyethylene bottle that was washed twice with water samples and sealed with sealing film. The samples were transported to the laboratory in an incubator at $4^{\circ} \mathrm{C}$ with a built-in ice bag and processed within 24 hours.

2.2. Enrichment and Cultivation of Sludge. To investigate the effect of artificial addition of denitrifying microbes on denitrification, the sludge containing denitrifying microbes was collected from the aeration tank of a sewage treatment plant $\left(35.94553^{\circ} \mathrm{N}, 120.21454^{\circ} \mathrm{E}\right)$, placed in a polyethylene bottle, transported to the laboratory at $25^{\circ} \mathrm{C}$, and treated and cultured within 24 hours.

The nutrient solution was prepared with distilled water, and the main components were $\mathrm{KNO}_{3}(0.37 \mathrm{~g} / \mathrm{L}), \mathrm{C}_{6} \mathrm{H}_{12} \mathrm{O}_{6}$ $(0.1562 \mathrm{~g} / \mathrm{L}), \mathrm{CH}_{3} \mathrm{OH}(320 \mathrm{uL} / \mathrm{L})$, and $\mathrm{KH}_{2} \mathrm{PO}_{4}(0.044 \mathrm{~g} / \mathrm{L})$.

The collected sludge was statically placed, and the supernatant was removed. The sedimentation of the lower layer of the sludge was packed into six $1 \mathrm{~L}$ conical bottles, which each contained $700 \mathrm{~mL}$. A total of $350 \mathrm{~mL}$ of the nutrient solution was added to each conical bottle and sparged with high-purity nitrogen for 5 minutes. They were then sealed with film designed to maintain freshness and film to seal to maintain the anaerobic environment and cultured at $25^{\circ} \mathrm{C}$ for 14 days. During the period of cultivation, the nutrient solution was changed every 48 hours. The supernatant in the conical bottle was removed, and then, $350 \mathrm{~mL}$ of the newly configured nutrient solution was added and sparged with high-purity nitrogen for 5 minutes. The bottles were sealed with both types of film and cultured at $25^{\circ} \mathrm{C}$. A volume of $350 \mathrm{~mL}$ of supernatant was discarded from the enriched sludge in each conical bottle, and all the excess sludge in the conical bottle was poured into a $5 \mathrm{~L}$ beaker and shaken well for inoculation. The settling ratio (SV\%) of the mixed sludge was $90 \%$. The concentration of the mixed sludge was $9838 \mathrm{mg} / \mathrm{L}$. The $\mathrm{C} / \mathrm{N}$ ratio of the mixed sludge was 16.3 .

2.3. Experimental Design. In this study, two groups of experiments were designed to investigate the efficiency of denitrification of native denitrifying microbes in 
groundwater and artificially added denitrifying microbes. Four conditions were established in each group, which were anaerobic, anaerobic with an added carbon source, aerobic, and aerobic with an added carbon source conditions. The anaerobic conditions were introduced by sparging with high-purity nitrogen for 3 minutes and sealing the bottle cap with sealing film.

Analytically pure glucose was used as the sole carbon source for microbial growth, and its concentration was controlled as $1 \mathrm{~g} / \mathrm{L}$. Each time, $100 \mathrm{~mL}$ of water samples was taken and placed in $150 \mathrm{~mL}$ volume serum bottles. The $15 \mathrm{~mL}$ of sludge that was cultured and enriched was inoculated to water. The serum bottle was placed in a BOD constant temperature incubator (American Hash Company, 205-2). The temperature was controlled at $15^{\circ} \mathrm{C}$. The water samples were collected, and the indices were determined every 24 hours. The control consisted of three parallel samples. The specific experimental design is shown in Figure 1.

2.4. Test Index and Determination Method. The experimental indices include the $\mathrm{pH}$, Oxidation-Reduction Potential (ORP), nitrate nitrogen $\left(\mathrm{NO}_{3}{ }^{-}-\mathrm{N}\right)$, nitrite nitrogen $\left(\mathrm{NO}_{2}{ }^{-}-\right.$ $\mathrm{N})$, and ammonia nitrogen $\left(\mathrm{NH}_{4}{ }^{+}-\mathrm{N}\right)$.

The supernatant of cultured water samples was tested, in which the $\mathrm{pH}$ and ORP were determined directly. The water samples were then filtered through a $0.45 \mu \mathrm{m}$ filter membrane to determine the amounts of nitrate nitrogen $\left(\mathrm{NO}_{3}{ }^{-}-\right.$ $\mathrm{N})$, nitrite nitrogen $\left(\mathrm{NO}_{2}{ }^{-}-\mathrm{N}\right)$, and ammonia nitrogen $\left(\mathrm{NH}_{4}{ }^{+}-\mathrm{N}\right)$. All of the detection methods were conducted in accordance with the national standard method [48], and the main analytical methods are shown in Table 1.

2.5. Data Processing and Drawing Methods. The mean and standard deviation of three parallel samples were calculated under each culture condition. Origin software (OriginLab, Northampton, MA, USA) was used to draw the figures.

the removal rate of nitrate nitrogen $=\frac{\text { reduced } \text { nitrate nitrogen }}{\text { initial } \text { nitrate nitrogen }} \cdot 100 \%$.

\section{Results and Discussion}

The results of two groups of experiments were compared to determine the effects of native denitrifying microbes in groundwater and denitrifying microbes that were artificially added on denitrification in groundwater with a high concentration of nitrate nitrogen.

3.1. Removal of Nitrate Nitrogen. The changes in concentration of nitrate nitrogen in water samples under the action of native denitrifying microbes are shown in Figure 2(a). The trend of change of concentration of nitrate nitrogen in the water samples under the four culture conditions was basically the same and unstable. During the culture period, there was both an increase and a decrease in nitrate nitrogen. The overall rate of removal increased during the first 5 days of the experiment. It reached its maximum value of $10 \%$ on day 4 under the condition of aerobic with an added carbon source. This indicated that denitrification occurred, and the degree of denitrification was the highest on day 4 . The nitrate nitrogen only increased on day 3 , possibly owing to ammoxidation [49]. The increase was the largest under the condition of anaerobic with an added carbon source, which changed from an initial concentration of $281.81 \mathrm{mg} / \mathrm{L}$ to $309.77 \mathrm{mg} / \mathrm{L}$. The overall rate of removal decreased from days 6 to 12 of the experiment as the nitrate nitrogen accumulated. The rate of removal under the anaerobic condition decreased to $0.78 \%$ on day 12 . In addition, from days 6 to 8 , the nitrate nitrogen increased continuously under the condition of anaerobic with an added carbon source. The change in concentration was slightly different from those under the other three conditions. The concentration of nitrate nitrogen under the other three conditions increased at first and then decreased.

As seen in Figure 2(a), the rate of removal of nitrate nitrogen in the water samples was not obvious under the four conditions. The denitrification efficiency cannot be effectively promoted by adding a carbon source and creating an anaerobic condition. The final concentration of nitrate nitrogen was close to that of the initial concentration, and there was basically no removal of nitrate nitrogen. This shows that the native denitrifying microbes in water samples cannot efficiently promote denitrification when glucose is added as a carbon source and whether oxygen is provided or not, so they were unable to reduce the high concentration of nitrate nitrogen in water samples.

In contrast, as shown in Figure 2(b), the denitrification efficiency of artificially added denitrifying microbes in the four culture conditions showed obvious differences with the passage of culture time. The concentration of nitrate nitrogen in the water samples decreased to varying degrees. The efficiency of denitrification was the most effective under the condition of anaerobic with an added carbon source. The rate of removal increased gradually with the duration of the experiment. On day 7 , the concentration of nitrate nitrogen decreased from an initial concentration of $266.2 \mathrm{mg} / \mathrm{L}$ to $27.9 \mathrm{mg} / \mathrm{L}$, and the rate of removal reached $89.52 \%$. The denitrification effect under the condition of aerobic with an added carbon source was less than that of anaerobic condition in which a carbon source was added. The concentration of nitrate nitrogen decreased gradually with the experiment, and the rate of removal gradually increased. On day 7 , the concentration of nitrate nitrogen decreased from the initial concentration of $266.2 \mathrm{mg} / \mathrm{L}$ to $103.8 \mathrm{mg} / \mathrm{L}$, and the rate of removal reached $55.16 \%$. Denitrification was not performed effectively under anaerobic or aerobic conditions, and the concentration of nitrate remained basically the same. During the experiment, the concentration of nitrate nitrogen increased and decreased but decreased as a whole. On day 7 under the anaerobic condition, the concentration of nitrate nitrogen decreased from an initial concentration of $266.2 \mathrm{mg} / \mathrm{L}$ to $220.3 \mathrm{mg} / \mathrm{L}$, and the rate of removal was $17.24 \%$. The concentration of nitrate nitrogen increased slightly on days 2 and 5 of the experiment, which may be 


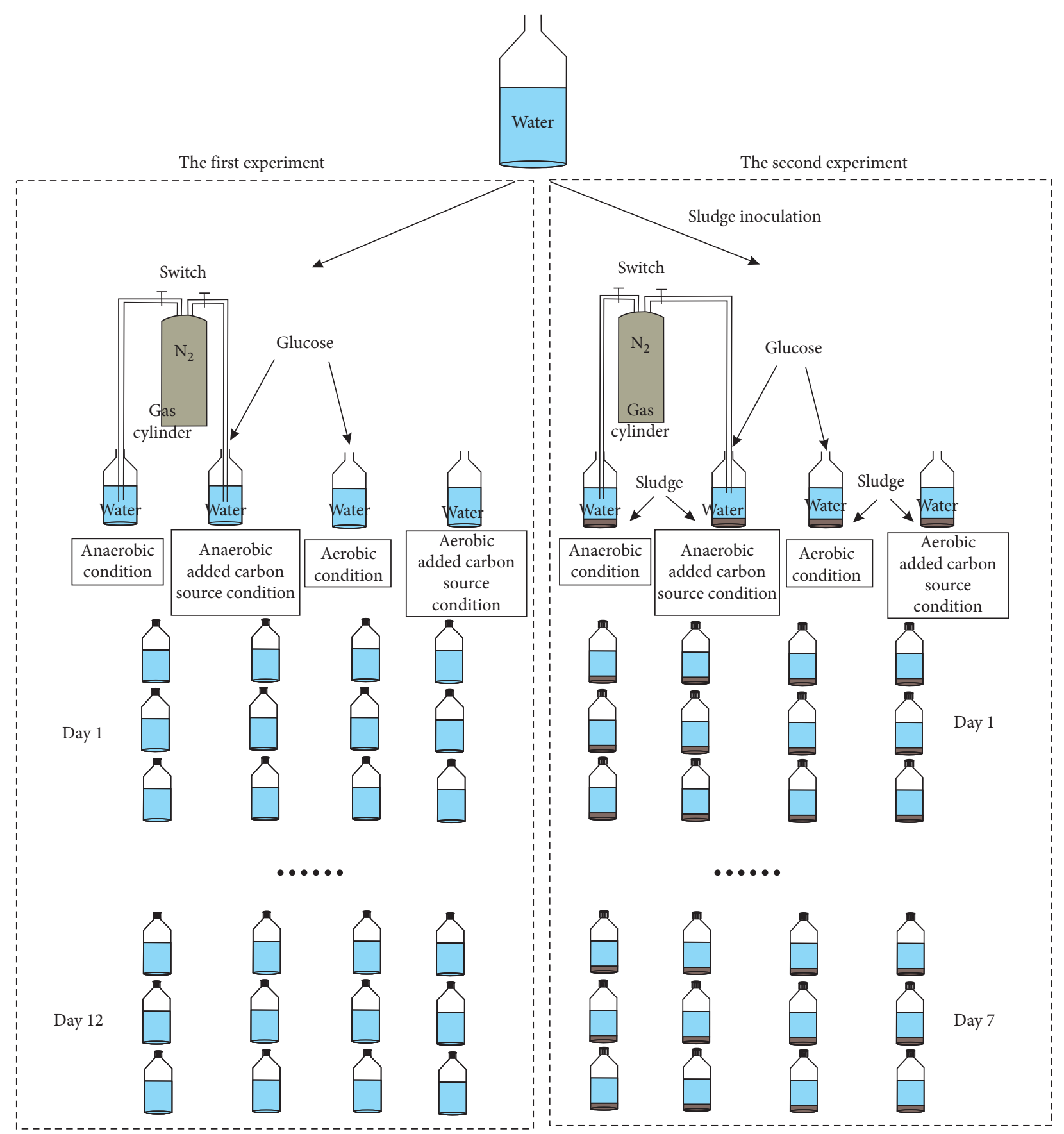

FIgURE 1: Diagram of the experimental design.

TABLE 1: Detection method of test index.

\begin{tabular}{lcc}
\hline Serial number & Index & Detection method \\
\hline 1 & $\mathrm{pH}$ & Hash electrode method \\
2 & $\mathrm{ORP}$ & Hash electrode method \\
3 & $\mathrm{NO}_{3}^{-}-\mathrm{N}$ & Ultraviolet spectrophotometry \\
4 & $\mathrm{NO}_{2}^{-}-\mathrm{N}$ & $\mathrm{N}$-(1-naphthyl)-ethylenediamine spectrophotometry \\
5 & $\mathrm{NH}_{4}^{+}-\mathrm{N}$ & Nessler's reagent spectrophotometry \\
\hline
\end{tabular}




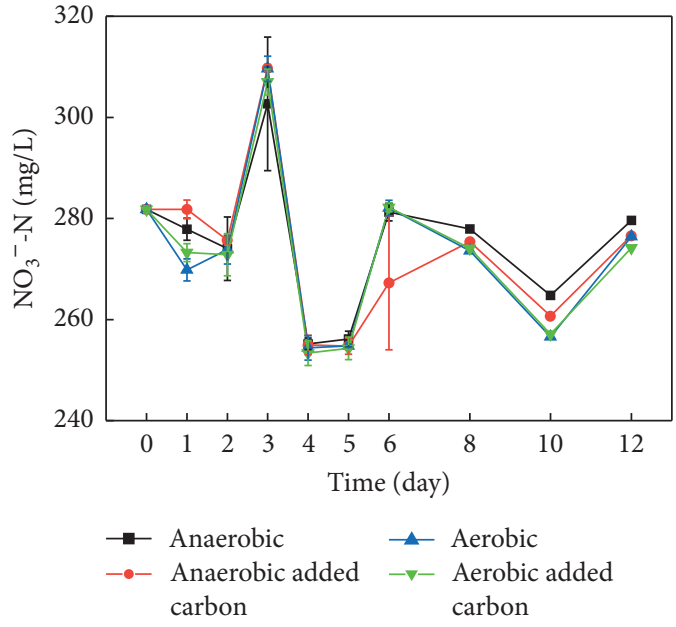

(a)

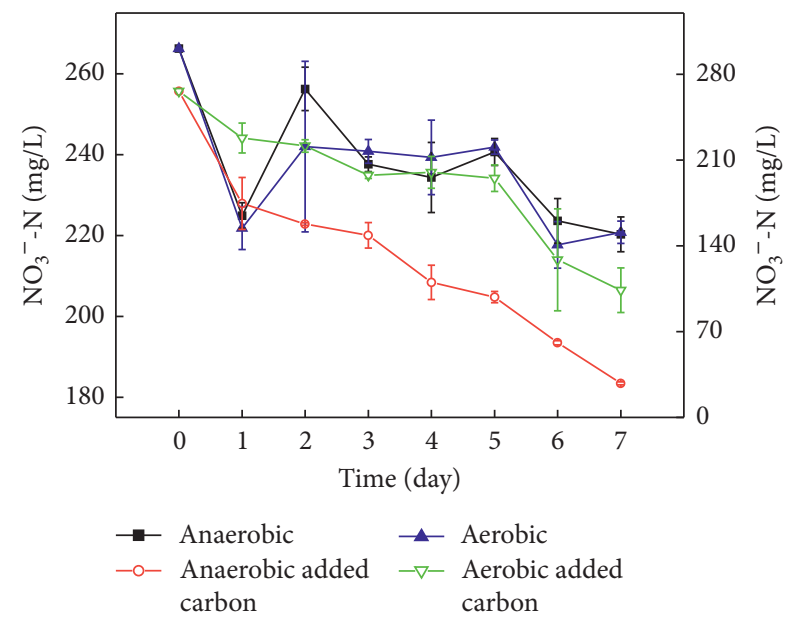

(b)

Figure 2: Changes in nitrate nitrogen. The solid point is based on the left longitudinal axis, and the hollow point is based on the right longitudinal axis.

owing to ammoxidation [49]. Under aerobic conditions, the concentration of nitrate nitrogen decreased from an initial concentration of $266.2 \mathrm{mg} / \mathrm{L}$ to $217.67 \mathrm{mg} / \mathrm{L}$, and on day 6 , the rate of removal was $18.23 \%$. The concentration of nitrate nitrogen increased slightly on days 2,5 , and 7 of the experiment, which may be owing to ammoxidation [49].

Comparing the experimental results of the two groups, there was a significant difference in the rate of removal of nitrate nitrogen under the influence of the two types of microbes. The rate of removal of nitrate nitrogen in the water samples in which artificially added denitrifying microbes had been added was significantly better than that under the action of native denitrifying microbes. In addition, the maximum rate of removal of nitrate nitrogen under the action of native denitrifying microbe was only $10 \%$. The rate of removal is not obvious, which shows that the native denitrifying microbes in groundwater are not capable of removing high concentrations of nitrate nitrogen in water samples. In addition, large amounts of denitrifying microbes are needed to promote the denitrification effect, so as to achieve the purpose of reducing high concentrations of nitrate nitrogen in groundwater.

In addition, when the changes in concentration of nitrate nitrogen of artificially added denitrifying microbe water samples under four culture conditions were compared, it can be seen that artificially added denitrifying microbes produced the strongest activity under anaerobic condition in which glucose was provided as a carbon source. It was highly effective at denitrifying a high concentration of nitrate nitrogen in groundwater with a rate of removal rate as high as $89.25 \%$. The experimental results showed that for the groundwater with a high concentration of nitrate nitrogen, the introduction of denitrifying microbes and the provision of an anaerobic environment while using glucose as a carbon source could significantly reduce the concentration of nitrate nitrogen in the groundwater. However, the lowest concentration of nitrate nitrogen in the water samples was $27.9 \mathrm{mg} / \mathrm{L}$, which still does not meet the quality standard of class III groundwater $(\leq 20 \mathrm{mg} / \mathrm{L})$. The experimental culture time was too short and did not provide adequate time for the complete denitrification of the nitrate nitrogen.

3.2. Accumulation of Nitrite Nitrogen. It can be seen in Figure 3(a) that under the action of native denitrifying microbes, the accumulation of nitrite nitrogen in the water samples under the four culture conditions was not obvious. The concentration of nitrite nitrogen increased at first and then decreased during the experiment. The change in concentration of nitrite nitrogen under the condition of anaerobic with an added carbon source was more obvious than that under the other three conditions. The concentration was the highest on day 12 of the experiment, which increased from an initial concentration of $0.004 \mathrm{mg} / \mathrm{L}$ to $0.6 \mathrm{mg} / \mathrm{L}$. The concentration of nitrite nitrogen under the condition of aerobic with an added carbon source changed more gradually than that under the condition of anaerobic with an added carbon source. Additionally, the concentration was highest on day 8 , representing an increase from an initial concentration of $0.004 \mathrm{mg} / \mathrm{L}$ to $0.123 \mathrm{mg} / \mathrm{L}$. With the progression of the experiment, the concentration of nitrite nitrogen decreased again, and the concentration decreased to $0.057 \mathrm{mg} / \mathrm{L}$ on day 12 of the experiment. The change in concentration of nitrite nitrogen under anaerobic and aerobic conditions tended to be consistent, and it was very small. After 12 days of culture, the concentration of nitrite nitrogen under the anaerobic condition changed from $0.004 \mathrm{mg} / \mathrm{L}$ to $0.008 \mathrm{mg} / \mathrm{L}$. Under the aerobic condition, the concentration of nitrite nitrogen changed from $0.004 \mathrm{mg} / \mathrm{L}$ to $0.009 \mathrm{mg} / \mathrm{L}$.

Thus, it can be seen that under the action of native denitrifying microbes, the accumulation of nitrite nitrogen in water samples under the four culture conditions was not obvious. The concentration of nitrate nitrogen was basically unchanged, which provides additional evidence that the degree of denitrification was not high enough. The native 


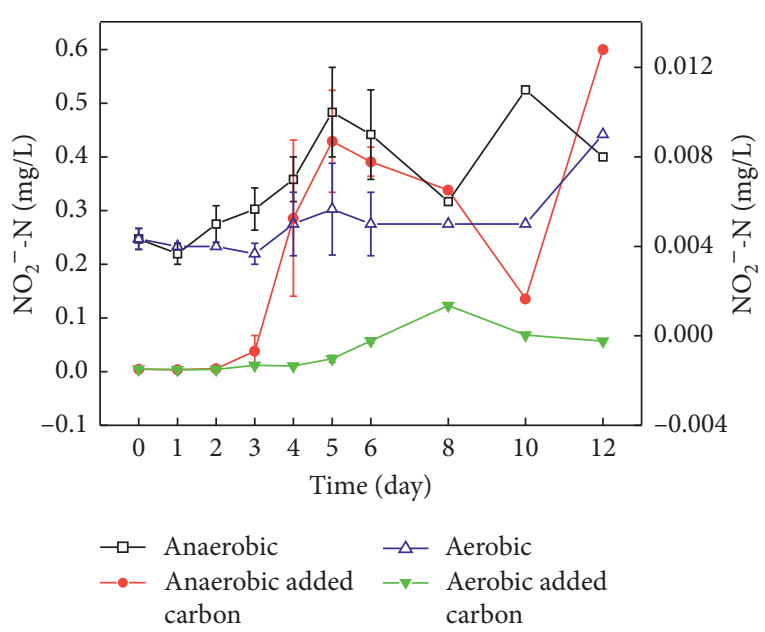

(a)

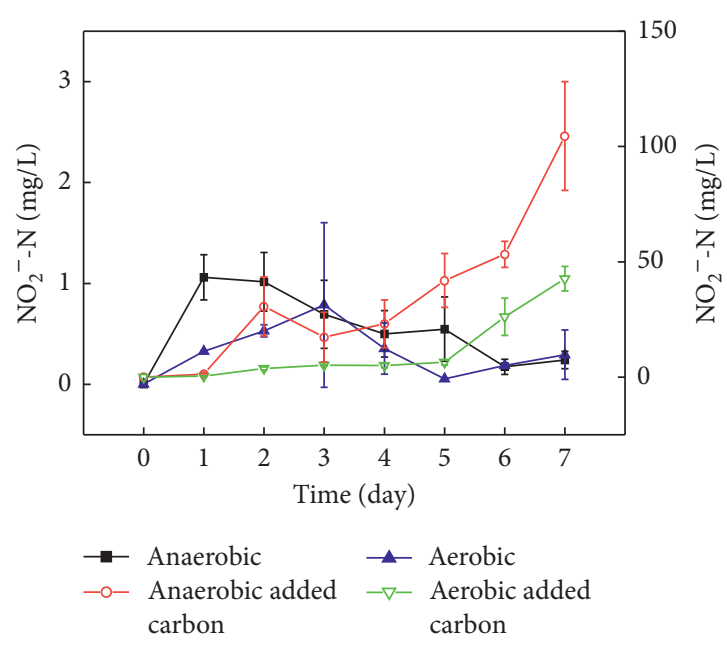

(b)

Figure 3: Changes in nitrite nitrogen. The solid point is based on the left longitudinal axis, and the hollow point is based on the right longitudinal axis.

denitrifying microbes in water samples failed to effectively promote denitrification under the combined conditions of whether or not glucose was added as a carbon source, and oxygen was provided.

As shown in Figure 3(b), the concentration of nitrite nitrogen in the water samples increased as a whole under anaerobic and aerobic conditions with an added carbon source, and nitrite nitrogen accumulated to greater amounts. The concentration of nitrite nitrogen in the anaerobic condition with an added carbon source increased the most significantly compared with the other three conditions, and the concentration increased from $0.003 \mathrm{mg} / \mathrm{L}$ to $104.533 \mathrm{mg} /$ L on day 7 of the experiment. Under the condition of aerobic with an added carbon source, the concentration of nitrite nitrogen increased significantly, from the concentration of $0.003 \mathrm{mg} / \mathrm{L}$ to $42.667 \mathrm{mg} / \mathrm{L}$ on day 7 of the experiment. The overall change in the concentrations of nitrite nitrogen under anaerobic and aerobic conditions was almost the same, showing a trend of increasing at first and then decreasing. Compared with the original water sample, there was an accumulation of nitrite nitrogen, but it was very low. Under the anaerobic condition, the concentration of nitrite nitrogen was the highest on the first day of the experiment and increased from $0.003 \mathrm{mg} / \mathrm{L}$ to $1.061 \mathrm{mg} / \mathrm{L}$. The concentration of nitrite nitrogen decreased again to $0.24 \mathrm{mg} / \mathrm{L}$ on day 7 of the experiment. Under the aerobic condition, the concentration of nitrite nitrogen was the highest on day 3 of the experiment, which resulted in an increase from $0.003 \mathrm{mg} / \mathrm{L}$ to $0.787 \mathrm{mg} / \mathrm{L}$. The concentration of nitrite nitrogen decreased again to $0.293 \mathrm{mg} / \mathrm{L}$ on day 7 of the experiment.

Under the action of artificially added denitrifying microbes, nitrite nitrogen in the water accumulated to varying degrees under the four culture conditions but only slightly under anaerobic and aerobic conditions. The accumulation under the conditions of anaerobic with an added carbon source and aerobic with an added carbon source was more obvious, particularly under the condition of anaerobic with an added carbon source. Simultaneously, the nitrate nitrogen declined the most quickly under the condition of anaerobic with an added carbon source, which showed that the denitrification effect was the strongest in the water sample under the condition of anaerobic with an added carbon source, and the artificially added denitrifying microbes played a role and effectively promoted denitrification.

Nitrite nitrogen is the intermediate product of the denitrification process, and this compound accumulated during both experiments. In addition, the faster the concentration of nitrate decreased, the more nitrite nitrogen accumulated, which is the incomplete embodiment of denitrification. The reason for this phenomenon could be that the culture time was not long enough; the reaction container was a serum bottle; the volume was fixed, and denitrification was not complete. During the process of denitrification, the rate of action of nitrate reductase is faster than that of nitrite reductase. Under the conditions suitable for denitrification, a large amount of nitrate can be rapidly reduced to nitrite, resulting in a large amount of accumulation. Only when denitrification is complete will the accumulation of nitrite gradually decrease. In addition, the culture temperature of this experiment was set at $15^{\circ} \mathrm{C}$. Zhang Lin et al. [50] found that the temperature had a substantial effect on the accumulation of nitrite nitrogen during the process of denitrification, decreasing the activity of the enzyme and inhibiting the transformation of nitrite nitrogen to ammonia nitrogen at $15^{\circ} \mathrm{C}$, thus, resulting in the accumulation of nitrite nitrogen. The factors that affect the rate of growth of $\mathrm{mi}-$ croorganisms, such as $\mathrm{C} / \mathrm{N}$ and the type of carbon source, also led to the accumulation of nitrite nitrogen [2,51-53]. At the beginning of the experiments, the concentration of carbon source was $1 \mathrm{~g} / \mathrm{L}$, and the $\mathrm{C} / \mathrm{N}$ was not well controlled. The lack of a carbon source in the latter stage of the reaction may also lead to the accumulation of nitrite nitrogen. In future experiments, we can choose a larger 
reaction container to prolong the continuous culture time and change the concentration of carbon source and the type of carbon source to explore the nutrient carbon source that can enhance the effect of microbial denitrification.

3.3. Accumulation of Ammonia Nitrogen. As shown in Figure 4(a), the concentration of ammonia nitrogen in water increased at first and then decreased under the four culture conditions. Additionally, ammonia nitrogen did not obviously accumulate during the experiment. Under the anaerobic condition, the concentration of ammonia nitrogen reached its maximum on day 3 and increased from $0.037 \mathrm{mg} / \mathrm{L}$ to $0.39 \mathrm{mg} / \mathrm{L}$. As the experiment continued, the concentration of ammonia nitrogen decreased to $0.163 \mathrm{mg} / \mathrm{L}$ on day 5 and tended to be stable. The concentration of ammonia nitrogen was $0.14 \mathrm{mg} / \mathrm{L}$ on day 12 of the experiment. Under the condition of anaerobic with an added carbon source, the change of ammonia nitrogen concentration was small, and the trend was relatively moderate. The concentration of ammonia nitrogen reached its maximum on day 2 of the experiment, increasing from $0.037 \mathrm{mg} / \mathrm{L}$ to $0.157 \mathrm{mg} / \mathrm{L}$ and gradually stabilizing with the experiment. The concentration was $0.07 \mathrm{mg} / \mathrm{L}$ on day 12 of the experiment. The concentration of ammonia nitrogen under the anaerobic condition and the condition of anaerobic with an added carbon source barely changed and was less than $0.5 \mathrm{mg} / \mathrm{L}$, which meets the Chinese drinking water standard. Under the aerobic condition, the concentration of ammonia nitrogen increased from $0.037 \mathrm{mg} / \mathrm{L}$ to $0.27 \mathrm{mg} / \mathrm{L}$ on the first day, then decreased to $0.123 \mathrm{mg} / \mathrm{L}$ on day 3 , and stabilized from days 3 to 6 . With the progress of the experiment, the concentration increased rapidly from days 6 to 8, reached a maximum value of $0.56 \mathrm{mg} / \mathrm{L}$ on day 8 , decreased gradually, and then decreased to $0.03 \mathrm{mg} / \mathrm{L}$ on day 12 of the experiment. Compared with the original water sample, there was no accumulation of ammonia nitrogen. Under the condition of aerobic with an added carbon source, ammonia nitrogen accumulated the most on day 5 , increased from the initial concentration of $0.037 \mathrm{mg} / \mathrm{L}$ to $0.27 \mathrm{mg} / \mathrm{L}$, decreased to 0 on day 6 , and then almost no longer accumulated.

The formation of ammonium suggested that dissimilatory nitrate reduction to ammonia (DNRA) was occurring. DNRA is a side reaction of denitrification and competes with denitrification [54-56]. The balance of denitrification and DNRA depends on temperature, oxygen, nitrate availability, and organic carbon [54, 57]. Some data showed that using glucose as an organic carbon source can easily stimulate the formation of ammonia nitrogen [58]. Ammonia nitrogen is unstable and easily oxidized to nitrate. Under the aerobic condition, the concentration of ammonia nitrogen increased significantly only on the first day and from days 6 to 8 . Under the aerobic condition with an added carbon source, the concentration of ammonia nitrogen only increased from days 3 to 5 , which could be owing to the decrease in nitrate concentration and the occurrence of DNRA reaction. In addition, the concentration of ammonia nitrogen was less than $0.2 \mathrm{mg} / \mathrm{L}$ during the whole experiment. Anaerobic condition with an added carbon source is more conducive to denitrification, less nitrate is dissimilated to ammonium, and the concentration of ammonia nitrogen was always less than $0.2 \mathrm{mg} / \mathrm{L}$. Under the anaerobic condition, ammonia nitrogen is not easily oxidized, and the concentration of ammonia nitrogen increased many times over the course of the experiment.

As seen in Figure 4(b), the change of ammonia nitrogen under the conditions of anaerobic with an added carbon source and aerobic with an added carbon source was basically the same, and the trend line is relatively smooth, showing a trend of increasing at first and then decreasing. Under the anaerobic condition, the concentration of ammonia nitrogen reached its maximum on day 2 and increased from $0.08 \mathrm{mg} / \mathrm{L}$ to $0.54 \mathrm{mg} / \mathrm{L}$. With the progression of the experiment, the concentration decreased gradually to $0.3 \mathrm{mg} / \mathrm{L}$ on day 7 . Under the condition of aerobic with an added carbon source, the concentration of ammonia nitrogen reached its maximum on day 3 and increased from $0.08 \mathrm{mg} / \mathrm{L}$ to $2.4 \mathrm{mg} / \mathrm{L}$. The concentration decreased gradually during the course of the experiment, dropping to $0.617 \mathrm{mg} / \mathrm{L}$ on day 7 of the experiment. Under the condition of anaerobic with an added carbon source, the concentration of ammonia nitrogen increased as a whole. It consistently accumulated during the first 3 days of the experiment from an initial concentration of $0.08 \mathrm{mg} / \mathrm{L}$ to the maximum concentration of $3.67 \mathrm{mg} / \mathrm{L}$ and decreased to $0.67 \mathrm{mg} / \mathrm{L}$ on day 4. It then increased gradually with the progress of the experiment, reaching $3.15 \mathrm{mg} / \mathrm{L}$ on day 7 of the experiment. Under the aerobic condition, the concentration of ammonia nitrogen increased at first and then decreased. The trend line fluctuated greatly. The accumulation of ammonia nitrogen was the highest on day 2 of the experiment, representing an increase from $0.08 \mathrm{mg} / \mathrm{L}$ to $0.92 \mathrm{mg} / \mathrm{L}$. With the progress of the experiment, it decreased to 0 on day 6 and remained stable until the end of the experiment.

Denitrification and DNRA are two processes that exist simultaneously and compete with each other in both aerobic and anaerobic environments. Under the aerobic condition and the condition of aerobic with an added carbon source, ammonia nitrogen obviously accumulated only on day 2 owing to DNRA, but with the progress of the experiment, the ammonia nitrogen was easily oxidized; the concentration decreased gradually, and the final concentration was low. Additionally, the concentration of ammonia nitrogen gradually decreased to 0 under aerobic conditions. On the whole, the accumulation of ammonia nitrogen in the water sample under the condition of anaerobic with an added carbon source was more obvious than that under the other three conditions. Ammonia nitrogen is not easily oxidized, and the DNRA process produces ammonia nitrogen, while glucose as a carbon source readily stimulates the formation of ammonia nitrogen [58]. However, not much of this compound accumulates. Ammonia oxidation [49] may have only occurred on day 4 , and the concentration of ammonia nitrogen decreased. Under anaerobic conditions, ammonia nitrogen is not easily oxidized. However, owing to the addition of denitrifying bacteria, the amount of denitrification is relatively strong. DNRA only occurs at the beginning of the experiment, and a small amount of ammonia nitrogen accumulates. 


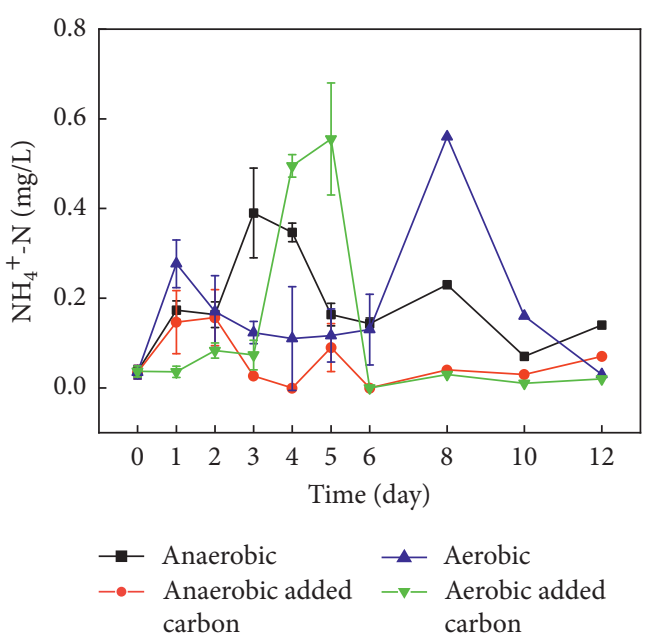

(a)

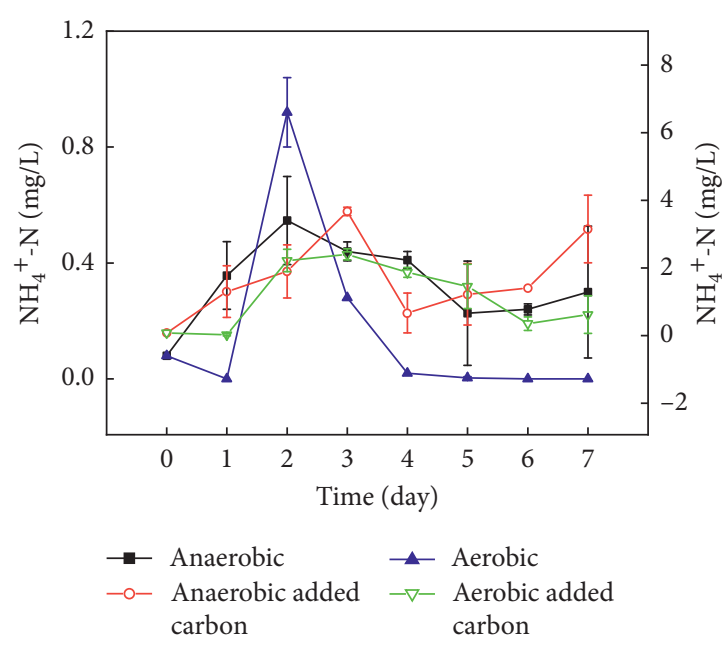

(b)

Figure 4: Changesin ammonia nitrogen. The solid point is based on the left longitudinal axis, and the hollow point is based on the right longitudinal axis.

At the beginning of the experiment, ammonia nitrogen accumulated to varying degrees under the four culture conditions, which may be owing to the sufficient dissolved organic matter or added carbon source in the water sample at the initial stage, and the dissimilation of nitrate nitrogen to ammonia nitrogen under the action of artificially added denitrifying microbes and native denitrifying microbes in water. In the latter stage, the denitrification effect gradually became strong, the effect of DNRA was weakened, and the difference of the four culture conditions led to a difference in the final accumulation of ammonia nitrogen.

In the two groups of experiments, the accumulation of ammonia nitrogen was not obvious as a whole, and there was only a certain accumulation of ammonia nitrogen in the water when denitrifying microbes were added artificially under the condition of anaerobic with an added carbon source. It is hypothesized that the reason for this phenomenon could be that the DNRA process and the existence of microorganisms and anaerobic conditions with an added carbon source promote the activity of microorganisms and increase the rate of release of ammonia nitrogen.

3.4. Changes in $p H$. The changes in $\mathrm{pH}$ in water under four culture conditions are shown in Figure 5(a). The change of $\mathrm{pH}$ under anaerobic and aerobic conditions was basically the same, and the whole trend increased at first and then decreased. On the first day, the water samples changed from weakly acidic to weakly alkaline and maintained this alkaline environment throughout the experiment. Combined with the change in nitrate nitrogen, denitrification occurred at the beginning of the experiment, the production of alkaline substances increased the $\mathrm{pH}$, and the water sample was weakly alkaline [59]. There was a sudden increase in $\mathrm{pH}$ from day 6 to 8 of the experiment. The $\mathrm{pH}$ increased to 8.24 under anaerobic conditions and to 7.85 under aerobic conditions. Combined with the change in nitrate nitrogen, this may be owing to the enhancement of denitrification and the production of alkaline substances [59]. The $\mathrm{pH}$ value increased. With the progress of the experiment, the $\mathrm{pH}$ gradually decreased. On day 12 of the experiment, the $\mathrm{pH}$ decreased to 7.36 under anaerobic conditions and to 7.11 under aerobic conditions. The natural denitrifying microbes in the water samples can produce organic acids [59] by biochemical reactions with the help of original organic matter, resulting in a gradual decrease in the $\mathrm{pH}$. The change in $\mathrm{pH}$ was basically the same under the conditions of anaerobic with an added carbon source and aerobic with an added carbon source. On the first day of the experiment, the water samples changed from weakly acidic to weakly alkaline, but the trend line was relatively smooth. Additionally, the water sample was weakly alkaline all of the time. On day 12 of the experiment, the $\mathrm{pH}$ was 7.05 under the condition of anaerobic with an added carbon source and 7.11 under the condition of aerobic with an added carbon source. Combined with the change in nitrate nitrogen, denitrification occurred at the beginning of the experiment, and the production of alkaline substances increased the $\mathrm{pH}$. The water sample was weakly alkaline [59].

As shown in Figure 5(b), the change in $\mathrm{pH}$ under anaerobic and aerobic conditions was basically the same. The trend line was relatively flat, and the value changed from 6.68 to 7.5. The water sample was weakly alkaline. Under the condition of anaerobic with an added carbon source, the change in $\mathrm{pH}$ was relatively smooth. The value always fluctuated around 6.68, but it was always less than 7, and the water sample was weakly acidic. Under the condition of aerobic with an added carbon source, the $\mathrm{pH}$ fluctuated greatly, and the value changed from 6.68 to 8.2 . The sample fluctuated from 5 to 8.5 . Owing to the alkaline substance produced by denitrification [59], the water sample changed from weakly acidic to weakly alkaline on the first day. It became acidic from day 2 to 5 , which may be owing to the strong biochemical effect of microbes using external a carbon source 


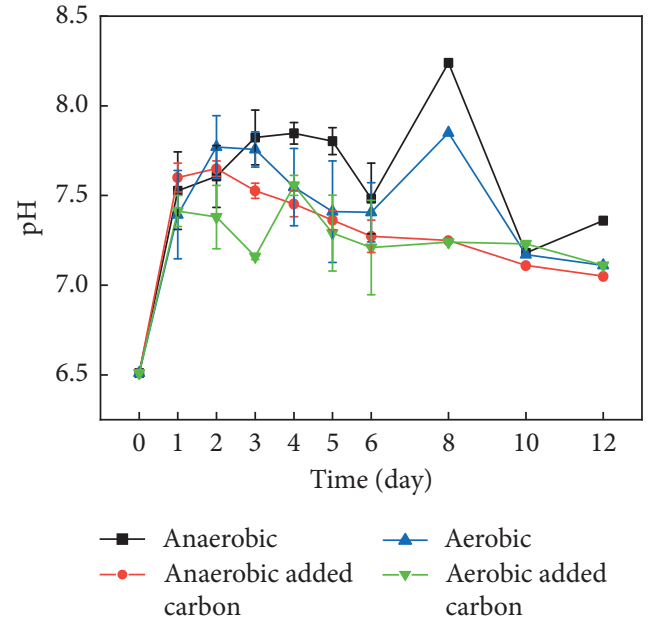

(a)

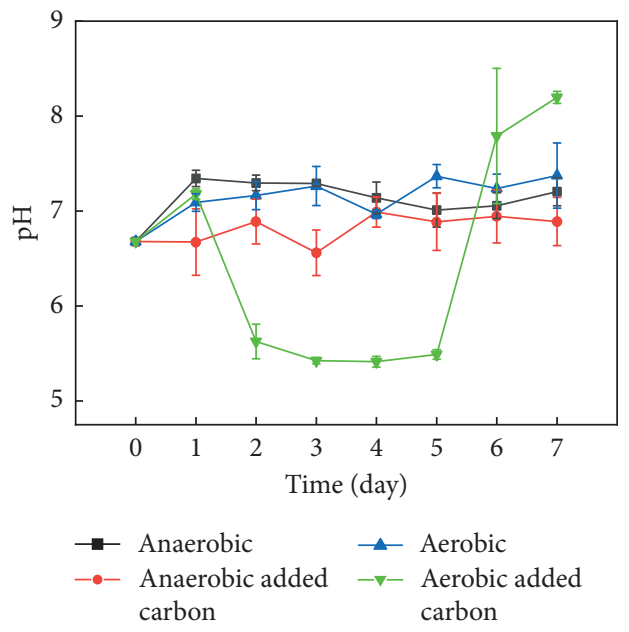

(b)

FIgURE 5: Changes in $\mathrm{pH}$.

and the production of more organic acids [59]. In addition, the $\mathrm{pH}$ was between 5 and 6 . It became weakly alkaline from day 6 to 7 . Combined with the change in nitrate nitrogen, the amount of denitrification was stronger during this period, resulting in an increase in the $\mathrm{pH}$.

Denitrification itself can increase the $\mathrm{pH}$ by releasing $\mathrm{CO}_{2}$ and hydroxide $\left(\mathrm{OH}^{-}\right)$. Normally, these combine to yield $\mathrm{HCO}_{3}{ }^{-}$, but if the production of $\mathrm{OH}^{-}$exceeds that of $\mathrm{CO}_{2}$, the $\mathrm{pH}$ can increase [60]. The dynamic balance of alkaline substances produced by denitrification and organic acids produced by biochemical reactions will affect the change in the $\mathrm{pH}$ of the system.

Under the action of artificially added denitrifying microbes, combined with the changes in nitrate nitrogen, the changes in $\mathrm{pH}$ in water samples as a whole were visible. Under anaerobic and aerobic conditions, the water sample was maintained in a weakly alkaline environment, which could be that more alkaline substances were produced by denitrification than organic acids produced by biochemical action [59]. And it was in a relatively stable state, so that the $\mathrm{pH}$ value of the water sample was more stable. Under the condition of anaerobic with an added carbon source, the water sample was maintained in the weakly acidic environment. The reaction was relatively strong, and more organic acids were produced following the addition of glucose as the carbon source. Additionally, denitrification was very strong, and the two effects were in a state of equilibrium to ensure that the water sample maintained a weakly acidic environment. The substantial change of $\mathrm{pH}$ value under the condition of aerobic with an added carbon source may be owing to the instability of denitrification and biochemical reactions under these culture conditions.

Too high or too low a $\mathrm{pH}$ value will affect the denitrification effect. Although denitrification still occurs when the $\mathrm{pH}$ value exceeds the optimal range, it may lead to the accumulation of intermediate toxic products (such as nitrite) [50]. When the changes of $\mathrm{pH}$ in the two groups of experiments were compared and connected with the changes in nitrate nitrogen and nitrite nitrogen concentration under different conditions, a $\mathrm{pH}$ value between 6.5 and 7 was found to be suitable for the growth and reproduction of denitrifying microbes. It aided in denitrification.

3.5. Changes in the ORP. As shown in Figure 6(a), the change of ORP under anaerobic and aerobic conditions was basically the same and showed a downward trend as a whole. The ORP fluctuated greatly from days 4 to 10 of the experiment. On day 12 of the experiment, the ORP decreased from $211.2 \mathrm{mV}$ to $132 \mathrm{mV}$ under anaerobic conditions. In addition, the ORP decreased from $211.2 \mathrm{mV}$ to $146.1 \mathrm{mV}$ under aerobic conditions. Under the conditions of anaerobic with an added carbon source and aerobic with an added carbon source, the change in ORP was basically the same. It showed a downward trend as a whole, and the trend line in the later stage of the experiment was relatively flat. On day 12 of the experiment, the ORP decreased from $211.2 \mathrm{mV}$ to $149.4 \mathrm{mV}$ under the condition of anaerobic with an added carbon source, and the ORP decreased from $211.2 \mathrm{mV}$ to $154.4 \mathrm{mV}$ under the condition of aerobic with an added carbon source.

The ORP can characterize the relative degree of oxidation or reduction. When the ORP is positive, the solution can oxidize to some extent. When the ORP is negative, the solution shows some degree of reduction. Its numerical change reflects the relative change of oxidation and reduction. The ORP decreased on the first day of the experiment. Combined with the change in nitrate nitrogen, it showed that denitrification occurred, the ability to oxidize decreased, and reduction occurred in the system. With the progress of the experiment, the ORP fluctuated and gradually stabilized, indicating that denitrification and ammonia oxidation occurred in the system. Denitrification is a reduction and will reduce the ability to oxidize and ORP. Ammonia oxidation consists of oxidation, which will increase the ability to oxidize and ORP. The change in ORP reflected the relative degree of denitrification and 


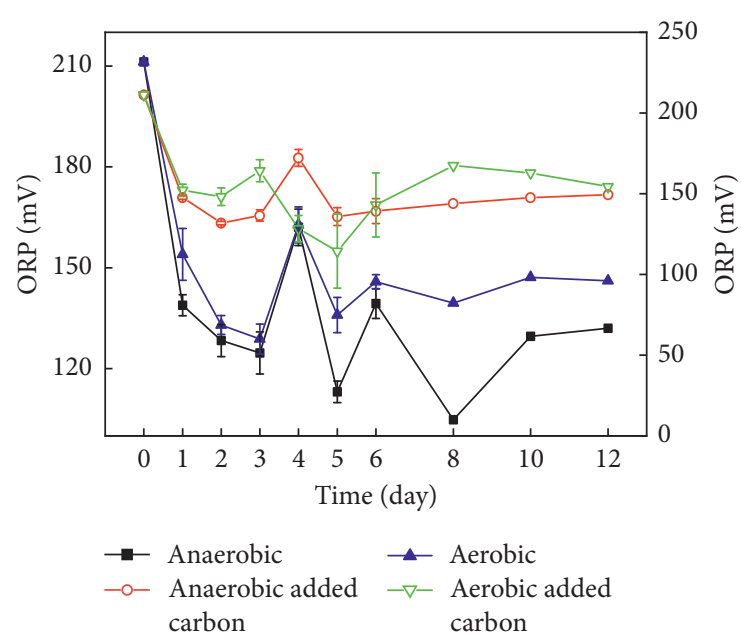

(a)

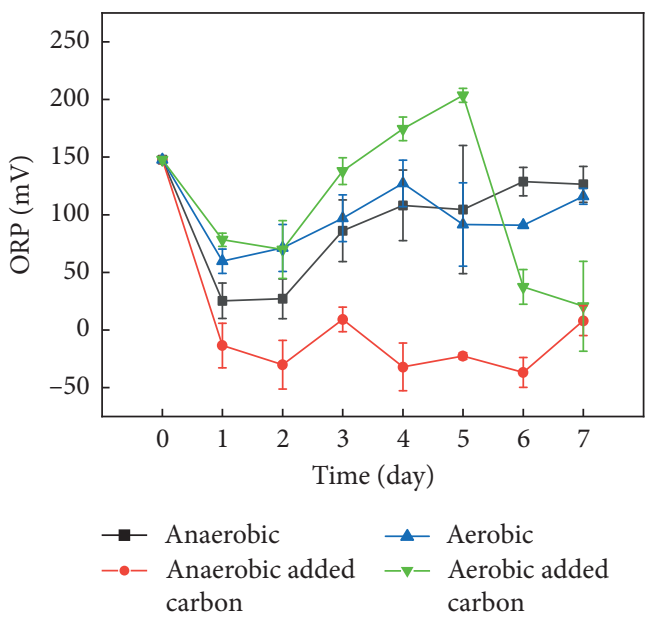

(b)

FIgURE 6: Changes in ORP. The solid point is based on the left longitudinal axis, and the hollow point is based on the right longitudinal axis.

ammoxidation. Thus, it can be seen that there was some ability to oxidize in the water under the four culture conditions. Denitrification occurred in the water, but it was not strong enough to make the water sample reductive.

As shown in Figure 6(b), the changes of ORP under anaerobic and aerobic conditions were basically the same, showing a trend of decreasing at first and then increasing. Under anaerobic conditions, the ORP decreased from $147.8 \mathrm{mV}$ to $27.1 \mathrm{mV}$ on the first day, and the tendency to oxidize in the water sample decreased. It then gradually increased with the progress of the experiment. The ORP increased to $126.33 \mathrm{mV}$ on day 7. Under aerobic conditions, the ORP decreased from $147.8 \mathrm{mV}$ to $59.7 \mathrm{mV}$ on the first day, and the tendency of the water sample to oxidize decreased. It then gradually increased with the progress of the experiment. The ORP increased to $116.03 \mathrm{mV}$ on day 7 . Combined with the changes of nitrate nitrogen under these two conditions, denitrification was strong at the beginning of the experiment owing to the artificial addition of denitrifying microbes. The ORP decreased rapidly on the first day, and the ability of the water sample to oxidize decreased. With the progress of the experiment, ammoxidation occurred in the system to enhance the ability of the water to oxidize, and the ORP gradually increased. Simultaneously, there was no carbon source added. Because of the lack of organic carbon in water, the weakening of denitrification may also lead to an increase in ORP.

Under the condition of aerobic with an added carbon source, the ORP decreased during the first 5 days and then increased. At the beginning of the experiment, owing to the artificial addition of the denitrifying microbes and the addition of a carbon source, the process of denitrification was strong. Additionally, the ORP decreased rapidly on days 1 and 2, and the ability of the water sample to oxidize weakened. In the later stage, the aerobic environment enhanced the occurrence of ammoxidation, the ORP increased, and the ability to oxidize increased. The ORP then quickly decreased to $20.6 \mathrm{mV}$ from days 6 to 7 . Combined with the changes in nitrate nitrogen, denitrification was enhanced, and the ability of water samples to oxidize decreased during this period. Under the condition of anaerobic with an added carbon source, the changes in the ORP showed a downward trend as a whole, which decreased rapidly to a negative value on the first day. The trend line changed smoothly from days 2 to 7 . Most of the ORP had a negative value. In the reaction system, denitrification was the strongest, ammoxidation was relatively weak, and the water samples showed a tendency to be reduced.

The ORP value reflected the redox property to some extent. A comparison of the data of two groups of experiments indicated that the water sample with artificially added denitrifying microbes showed some degree of reducibility under the condition of anaerobic with an added carbon source, which was beneficial to denitrification.

The experimental results showed that with the effect of the artificial addition of denitrifying microbes, the denitrification effect was the most effective under the condition of anaerobic with an added carbon source, which could effectively reduce the content of nitrate nitrogen. During the course of the experiment, the amount of nitrate nitrogen continuously decreased, and the rate of removal was the highest. Both nitrite nitrogen and ammonia nitrogen accumulated. Ammonia nitrogen accumulated to a lower degree, and the accumulation of nitrite was obvious. Sludge as denitrifying microbe can effectively promote denitrification.

Future areas of research will involve how to reduce the accumulation of nitrite nitrogen at the same time as removing the nitrate nitrogen and completely promoting denitrification and how to better apply bioremediation to the actual remediation of groundwater pollution.

\section{Conclusions}

Through two groups of laboratory experiments, this paper explored the feasibility and effectiveness of native denitrifying and artificially added denitrifying microbe sat 
removing high concentrations of nitrate nitrogen in groundwater under different combinations of oxygen and carbon source.

Under the setting of four culture conditions, the concentration of nitrate nitrogen in the water sample that was subjected to native denitrifying microbes basically changed the same amount, and the change was unstable. There were processes of both reduction and an increase in nitrate nitrogen. In addition, the highest rate of removal of nitrate nitrogen was only $10 \%$. This percentage is inadequate for remediation effects. The native denitrifying microbes in the water lacked the ability to remove the high concentration of nitrate nitrogen in the water sample.

Under the same four culture conditions, the concentration of nitrate nitrogen in water samples to which denitrifying microbes were artificially added changed significantly, and they decreased significantly with the increase in culture time. The change in concentration of nitrate nitrogen and the changes in nitrite nitrogen, ammonia nitrogen, $\mathrm{pH}$, and ORP can reflect the ability of denitrifying microbes to remove nitrate nitrogen in the water under the four culture conditions. The removal was most effective under the condition of anaerobic with an added carbon source, and the rate of removal reached as high as $89.52 \%$. In addition, the rate of removal under the condition of aerobic with an added carbon source was more effective, and the rate of removal was $55.16 \%$. The rate of removal under anaerobic and aerobic conditions was not very high, and both the removal rates were less than $20 \%$. Therefore, the artificially added denitrifying microbes have higher activity and a more significant effect under anaerobic conditions with the provision of glucose as a carbon source, which can effectively promote denitrification in water and reduce the concentration of nitrate nitrogen in the water.

Compared with the changes in five indices in water treated by microbes from different sources under the same culture condition, artificially added denitrifying microbes functioned significantly better than the native denitrifying microbes in water samples, which could better promote denitrification.

\section{Data Availability}

The raw data required to reproduce these findings cannot be shared at this time as the data also form part of an ongoing study.

\section{Conflicts of Interest}

The authors declare that there are no conflicts of interest regarding the publication of this article.

\section{Acknowledgments}

This research was supported by the Scientific Research Foundation of Qingdao Geo-Engineering Surveying Institute (No. 2019-QDDZYKY01).

\section{References}

[1] K. Ganesh, J. B. Joshi, and S. B. Sawant, "Cellulase deactivation in a stirred reactor," Biochemical Engineering Journal, vol. 4, no. 2, pp. 137-141, 2000.

[2] M. Gómez, E. Hontoria, and J. González-López, "Effect of dissolved oxygen concentration on nitrate removal from groundwater using a denitrifying submerged filter," Journal of Hazardous Materials, vol. 90, no. 3, pp. 267-278, 2002.

[3] M. Volokita, A. Abeliovich, and M. I. M. Soares, "Denitrification of groundwater using cotton as energy source," Water Science and Technology, vol. 34, no. 1-2, pp. 379-385, 1996.

[4] M. Volokita, S. Belkin, A. Abeliovich, and M. I. M. Soares, "Biological denitrification of drinking water using newspaper," Water Research, vol. 30, no. 4, pp. 965-971, 1996.

[5] K. B. Moore, B. Ekwurzel, B. K. Esser, G. B. Hudson, and J. E. Moran, "Sources of groundwater nitrate revealed using residence time and isotope methods," Applied Geochemistry, vol. 21, no. 6, pp. 1016-1029, 2006.

[6] Z. Qiao, R. Sun, Y. Wu et al., "Characteristics and metabolic pathway of the bacteria for heterotrophic nitrification and aerobic denitrification in aquatic ecosystems," Environmental Research, vol. 191, p. 110069, 2020.

[7] X. Liu, Y. Wu, R. Sun et al., " $\mathrm{NH}_{4}{ }^{+}-\mathrm{N} / \mathrm{NO}_{3}{ }^{-} \mathrm{N}$ ratio controlling nitrogen transformation accompanied with $\mathrm{NO}_{2}{ }^{-}-\mathrm{N}$ accumulation in the oxic-anoxic transition zone," Environmental Research, vol. 189, p. 109962, 2020.

[8] Z. Qiao, Y. Wu, J. Qian et al., "A lab-scale study on heterotrophic nitrification-aerobic denitrification for nitrogen control in aquatic ecosystem," Environmental Science and Pollution Research, vol. 27, no. 9, pp. 9307-9317, 2020.

[9] A. M. Fan, "Nitrate and nitrite in drinking water: a toxicological review," Encyclopedia of Environmental Health, pp. 137-145, 2011.

[10] S. Khademikia, Z. Rafiee, M. M. Amin, P. Poursafa, M. Mansourian, and A. Modaberi, "Association of nitrate, nitrite, and total organic carbon (TOC) in drinking water and gastrointestinal disease," Journal of Environmental and Public Health, vol. 20134 pages, 2013.

[11] P. M. Vitousek, J. D. Aber, R. W. Howarth et al., "Human alteration of the global nitrogen cycle: sources and consequences," Ecological Applications, vol. 7, no. 3, pp. 737-750, 1997.

[12] J. N. Kostraba, E. C. Gay, M. Rewers, and R. F. Hamman, "Nitrate levels in community drinking waters and risk of IDDM: an ecological analysis," Diabetes Care, vol. 15, no. 11, pp. 1505-1508, 1992.

[13] M. Qasemi, M. Farhang, H. Biglari et al., "Health risk assessments due to nitrate levels in drinking water in villages of Azadshahr, Northeastern Iran," Environmental Earthences, vol. 77 , no. 23 , p. 782,2018

[14] H. Rezaei, A. Jafari, B. Kamarehie et al., "Health-risk assessment related to the fluoride, nitrate, and nitrite in the drinking water in the Sanandaj, Kurdistan County, Iran," Human and Ecological Risk Assessment: An International Journal, vol. 25, no. 5, pp. 1242-1250, 2019.

[15] M. Hurtado-Martinez, B. Muñoz-Palazon, V. M. RoblesArenas, A. Gonzalez-Martinez, and J. Gonzalez-Lopez, "Biological nitrate removal from groundwater by an aerobic granular technology to supply drinking water at pilot-scale," Journal of Water Process Engineering, vol. 40, p. 101786, 2021.

[16] M. I. M. Soares, "Biological denitrification of groundwater," Environmental Challenges, vol. 40, pp. 183-193, 2000. 
[17] A. Abdelouas, L. Deng, E. Nuttall, W. Lutze, B. Fritz, and J.-L. Crovisier, "Réduction in situ des ions nitrate dans des eaux par les bactéries indigènes," Comptes Rendus de l'Académie des Sciences-Series IIA-Earth and Planetary Science, vol. 328, no. 3, pp. 161-166, 1999.

[18] P. M. Ayyasamy, K. Shanthi, P. Lakshmanaperumalsamy, S.-J. Lee, N.-C. Choi, and D.-J. Kim, "Two-stage removal of nitrate from groundwater using biological and chemical treatments," Journal of Bioscience and Bioengineering, vol. 104, no. 2, pp. 129-134, 2007.

[19] G. M. Cao, L. H. Zhang, M. Sheng, and Y. D. Liu, "Biological denitrification of groundwater by a composite membrane bioreactor," Environmental Engineering, vol. 864-867, pp. 2083-2089, 2014.

[20] X. Wang and J. Wang, "Removal of nitrate from groundwater by heterotrophic denitrification using the solid carbon source," Science in China Series B: Chemistry, vol. 52, no. 2, pp. 236-240, 2009.

[21] V. Matěj, S. Čižinská, J. Krejí, and T. Janoch, "Biological water denitrification-a review," Enzyme \& Microbial Technology, vol. 14, no. 3, pp. 170-183, 1992.

[22] R. B. Mellor, J. Ronnenberg, W. H. Campbell, and S. Diekmann, "Reduction of nitrate and nitrite in water by immobilized enzymes," Nature, vol. 355, no. 6362, pp. 717-719, 1992.

[23] N. Dineshkumar, C. Saravanakumar, M. Vasanth, M. Muralidhar, and S. V. Alavandi, "Genetic and physiological characterization of denitrifying bacteria from brackishwater shrimp culture ponds of India," International Biodeterioration \& Biodegradation, vol. 92, pp. 49-56, 2014.

[24] J. Smith, C. Wagner-Riddle, and K. Dunfield, "Season and management related changes in the diversity of nitrifying and denitrifying bacteria over winter and spring," Applied Soil Ecology, vol. 44, no. 2, pp. 138-146, 2010.

[25] W. J. Pabich, I. Valiela, and H. F. Hemond, "Relationship between DOC concentration and vadose zone thickness and depth below water table in groundwater of Cape Cod, USA," Biogeochemistry, vol. 55, no. 3, pp. 247-268, 2001.

[26] M. R. Trudell, R. W. Gillham, and J. A. Cherry, "An in-situ study of the occurrence and rate of denitrification in a shallow unconfined sand aquifer," Journal of Hydrology, vol. 83, no. 34, pp. 251-268, 1986.

[27] L. A. Schipper and M. Vojvodić-Vuković, "Nitrate removal from groundwater and denitrification rates in a porous treatment wall amended with sawdust," Ecological Engineering, vol. 14, no. 3, pp. 269-278, 2000.

[28] M. A. Robinson-Lora and R. A. Brennan, "The use of crabshell chitin for biological denitrification: batch and column tests," Bioresource Technology, vol. 100, no. 2, pp. 534-541, 2009.

[29] T. B. Moorman, T. B. Parkin, T. C. Kaspar, and D. B. Jaynes, "Denitrification activity, wood loss, and $\mathrm{N}_{2} \mathrm{O}$ emissions over 9 years from a wood chip bioreactor," Ecological Engineering, vol. 36, no. 11, pp. 1567-1574, 2010.

[30] L. A. Schipper, G. F. Barkle, J. C. Hadfield, M. VojvodicVukovic, and C. P. Burgess, "Hydraulic constraints on the performance of a groundwater denitrification wall for nitrate removal from shallow groundwater," Journal of Contaminant Hydrology, vol. 69, no. 3-4, pp. 263-279, 2004.

[31] C. Su and R. W. Puls, "Removal of added nitrate in cotton burr compost, mulch compost, and peat: mechanisms and potential use for groundwater nitrate remediation," Chemosphere, vol. 66, no. 1, pp. 91-98, 2007.
[32] S. Aslan and A. Turkman, "Nitrate and pesticides removal from contaminated water using biodenitrification reactor," Process Biochemistry, vol. 41, no. 4, pp. 882-886, 2006.

[33] M. A. Gómez, J. González-López, and E. Hontoria-Garćia, "Influence of carbon source on nitrate removal of contaminated groundwater in a denitrifying submerged filter," Journal of Hazardous Materials, vol. 80, no. 1-3, pp. 69-80, 2000.

[34] A. Mohseni-Bandpi and D. J. Elliott, "Groundwater denitrification with alternative carbon sources," Water Science and Technology, vol. 38, no. 6, pp. 237-243, 1998.

[35] A. Mohseni-Bandpi, D. J. Elliott, and A. Momeny-Mazdeh, "Denitrification of groundwater using acetic acid as a carbon source," Water Science and Technology, vol. 40, no. 2, pp. 53-59, 1999.

[36] N. Yan, X. Jin, and J. Zhang, "A compasrison between the processes of denitrification with glucose and methanol as carbon sourse," Journal of Shanghai Teachers University, vol. 31, no. 3, pp. 41-44, 2002.

[37] S. Zhang, Y. Zhang, F.-E. Zhang, and J. Jing, "Remediation of nitrate-contaminated groundwater in situ using a microecological techniques," Journal of Agro-Environmental Science, vol. 23, no. 6, pp. 1223-1227, 2004.

[38] Y. Zhang, S. Zhang, J. H. Jing, and H. B. Hou, "An experimental study of microbial removal of nitrogen pollutant from groundwater," Acta Geoscientica Sinica, vol. 27, no. 3, pp. 283-288, 2006.

[39] Y. Zhang, S. Zhang, C. L. Liu, X. Y. Wang, M. Zhang, and C. Song, "Experimental study on in-site remediation of groundwater polluted by nitrogen," China Water \& Wastewater, vol. 23, no. 11, pp. 8-12, 2007.

[40] S. Aslan and H. Cakici, "Biological denitrification of drinking water in a slow sand filter," Journal of Hazardous Materials, vol. 148, no. 1-2, pp. 253-258, 2007.

[41] C. D. Rocca, V. Belgiorno, and S. Meriç, "Heterotrophic/ autotrophic denitrification (HAD) of drinking water: prospective use for permeable reactive barrier," Desalination, vol. 210, no. 1-3, pp. 194-204, 2007.

[42] Z. Shen, Y. Yin, and J. Wang, "Biological denitrification using poly(butanediol succinate) as electron donor," Applied Microbiology and Biotechnology, vol. 100, no. 13, pp. 6047-6053, 2016.

[43] Z. Qiao, R. Sun, Y. Wu, S. Hu, X. Liu, and J. Chan, "Microbial heterotrophic nitrification-aerobic denitrification dominates simultaneous removal of aniline and ammonium in aquatic ecosystems," Water, Air, \& Soil Pollution, vol. 231, no. 3, p. 112, 2020.

[44] L. Wang, J. Li, X. Z. Song, and T. Z. Guo, "Isolation and identification of denitrifying bacteria from groundwater contaminated with nitrate of a typical intensive vegetable cultivation area," Ecology \& Environment, vol. 17, no. 5, pp. 2078-2081, 2008.

[45] X. L. Zhang and Y. X. Liang, "Screening of a strain denitrobacteria and its denitrification characteristic," Freshwater Fisheries, vol. 36, no. 5, pp. 28-32, 2006.

[46] X. L. Wang, "Study on in-situ microbial remediation of nitrate contaminated groundwater simulator," Hefei University of Technology, 2010.

[47] T. Li, W. Li, C. Feng, and W. Hu, "In-situ biological denitrification using pretreated maize stalks as carbon source for nitrate-contaminated groundwater remediation," Water Supply, vol. 17, no. 1, pp. 1-9, 2017.

[48] A. D. Eaton, L. S. Clesceri, A. E. Greenberg, and M. A. H. Franson, "Standard methods for the examination of 
water and wastewater," American Journal of Public Health and the Nation's Health, vol. 56, no. 3, pp. 387-388, 1966.

[49] R. J. Tu, W. Jin, S. F. Han et al., "Rapid enrichment and ammonia oxidation performance of ammonia-oxidizing archaea from an urban polluted river of China," Environmental Pollution, vol. 255, p. 113528, 2019.

[50] L. Zhang, L. N. Zheng, Y. N. Chen, J. N. Xiao, L. Zhang, and L. Wang, "Experimental study on removal of nitrate in groundwater with PRB," Journal of Tianjin University of Technology, vol. 30, no. 6, pp. 61-64, 2014.

[51] S. Ge, Y. Peng, S. Wang, C. Lu, X. Cao, and Y. Zhu, "Nitrite accumulation under constant temperature in anoxic denitrification process: the effects of carbon sources and COD/ $\mathrm{NO}_{3}$-N," Bioresource Technology, vol. 114, pp. 137-143, 2012.

[52] C. Glass and J. Silverstein, "Denitrification kinetics of high nitrate concentration water: $\mathrm{pH}$ effect on inhibition and nitrite accumulation," Water Research, vol. 32, no. 3, pp. 831-839, 1998.

[53] W. J. Hunter, "Accumulation of nitrite in denitrifying barriers when phosphate is limiting," Journal of Contaminant Hydrology, vol. 66, no. 1-2, pp. 79-91, 2003.

[54] O. Gibert, S. Pomierny, I. Rowe, and R. M. Kalin, "Selection of organic substrates as potential reactive materials for use in a denitrification permeable reactive barrier (PRB)," Bioresource Technology, vol. 99, no. 16, pp. 7587-7596, 2008.

[55] C. M. Greenan, T. B. Moorman, T. C. Kaspar, T. B. Parkin, and D. B. Jaynes, "Comparing carbon substrates for denitrification of subsurface drainage water," Journal of Environmental Quality, vol. 35, no. 3, pp. 824-829, 2006.

[56] B. M. Patterson, M. E. Grassi, G. B. Davis, B. S. Robertson, and A. J. McKinley, "Use of polymer mats in series for sequential reactive barrier remediation of ammonium-contaminated groundwater: laboratory column evaluation," Environmental Science \& Technology, vol. 36, no. 15, pp. 3439-3445, 2002.

[57] B. G. Ogilvie, M. Rutter, and D. B. Nedwell, "Selection by temperature of nitrate-reducing bacteria from estuarine sediments: species composition and competition for nitrate," FEMS Microbiology Ecology, vol. 23, no. 1, pp. 11-22, 1997.

[58] B. H. L. Kelso, R. V. Smith, and R. J. Laughlin, "Effects of carbon substrates on nitrite accumulation in freshwater sediments," Applied and Environmental Microbiology, vol. 65, no. 1, pp. 61-66, 1999.

[59] Z. T. Liu, Y. D. Chen, and Y. P. Jiang, "A preliminary study on removing nitrate in groundwater by using rice wine for the rural drinking water," Ground Water, vol. 37, no. 4, pp. 44-47, 2015.

[60] M. O. Rivett, S. R. Buss, P. Morgan, J. W. N. Smith, and C. D. Bemment, "Nitrate attenuation in groundwater: a review of biogeochemical controlling processes," Water Research, vol. 42, no. 16, pp. 4215-4232, 2008. 